\title{
Improvement of the Manufacturing of Aluminum Pots Using Lean Manufacturing Tools
}

\author{
Ximena Cusihuallpa-Vera, Evelyn Suarez-Montes ${ }^{(\bowtie)}$, \\ Juan Quiroz-Flores, and Jose Alvarez \\ Ingeniería Industrial, Unversidad Peruana de Ciencias Aplicadas, Lima, Peru \\ \{u201416312, u201414813, \\ juan.quiroz,pciijqui\}@upc.edu.pe
}

\begin{abstract}
The research is based on the problems encountered in the production process of companies in the metalworking sector. The problem arises from the low availability of machines in the production process due to working conditions $(39.5 \%)$, poor maintenance management $(40.3 \%)$ and poor-quality control $(20.2 \%)$ that generate low profitability for business. As a solution, Lean Manufacturing tools are implemented to improve the process and increase profitability. The improvement proposal consists of a series of stages: first, the definition of indicators for the measurement of the variables; then, the design and implementation of a pilot in the production process and, in parallel, a simulation system will be designed to evaluate the long-term results. The document concludes that the implementation of the proposed tools will increase the availability of machines and an OEE to $55 \%$, avoiding defective products and reducing reprocessed products by $4 \%$.
\end{abstract}

Keywords: Maintenance $\cdot$ Lean $\cdot$ Availability $\cdot$ Efficiency $\cdot$ Quality $\cdot$ Productivity $\cdot$ Metalworking

\section{Introduction}

Within the manufacturing sector, there is the metalworking industry which is an important component in the productive structure of the economy, due to its technological content and added value. In Peru, this industry represents $12 \%$ of the Gross Value Added (GVA) in the manufacturing industry and contributes $1.6 \%$ in the Gross Domestic Product (GDP). In addition, the metalworking industry is articulated with different industrial branches, to the point that all countries with advanced industrial development have a consolidated metalworking sector [1, 2]. However, the Ministry of Production, reported that the VAB of the metalworking industry in the last three years (2014-2016) had a 2.5\% decrease in annual average due to the contraction of the construction sector - the main demand of products of the metalworking industry (metal doors and windows, and metal structures) with a participation of $21 \%$ [3, 4].

The company under study, M1Pr2 is a Peruvian small firm oriented to the production and marketing of aluminum pots, and it is a representative sample of the 
manufacturing sector and the metalworking subsector. As a fact, the company does not have an area dedicated to the maintenance of its machines; so, any breakdown in the machines will paralyzed the production until the repairmen. Because the firm develops in a tight market, unforeseen failures generate issues regarding the time schedule of deliveries and fail to fully supply the demand. Therefore, the main problem that has been identified is the low availability of the machines in the production process. Due to this situation, the companies reduce its sales and lose competitiveness in the metalworking market.

This research study proposes an improvement in the production process in companies of the metalworking sector by implementing Lean Manufacturing tools to increasing profitability. The article will be distributed in 5 parts: first a brief introduction of the metalworking sector and the company under study; then, the theoretical framework will describe the tools to be implemented and the current situation of the company; later, the methodology section; then, the results; finally, the conclusion and recommendations.

\section{Problem}

For the present investigation, the studied company was M1Pr2, a Peruvian small company focused in the production and marketing of aluminum pots.

The main problem found was the low availability of the machines. Therefore, the following study analyses the monthly global efficiency (OEE) - based on calculations of availability, efficiency and quality - of each of their machines working on the pot production process.

\section{State of the Art}

Gujar and Moroliya [3] have worked on increasing productivity by studying work in a manufacturing industry. The problem was low productivity in the manufacturing industry due to the fatigue of the workers since they made additional time and effort to supply the demand. For this, they implemented talent management, obtaining greater morale from workers with increased safety and efficiency, high levels of production and optimization of the use of resources and lower production costs.

Moscoso [5] worked on product quality problems due to failures in the production process machines. For their solution, they created a preventive maintenance plan under a maintenance method focused on reliability, improving performance in the production process which improved the quality of their products, increased their competitiveness in the market and reduced their production costs.

\section{Innovative Proposal}

The innovative proposal for the solution of the problem is presented in Fig. 1. 


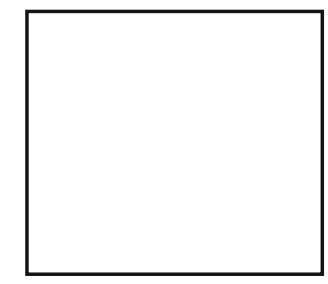

Fig. 1. Design of the innovative proposal

For the design of the proposed solution model, the implementation of three tools is proposed: Maintenance Management, Jidoka and Supplier Approval, which contribute to the improvement of the production process as well as the issues of machine availability, quality management and an adequate selection of suppliers.

\section{Results}

\subsection{Talent Management}

The implementation of this tool was carried out for the evaluation of working conditions. In order to identify the current situation, the performance was evaluated by labor competencies to measure the work of the operators which resulted in them having a score that varies between 10 and 12 points (poor). This was one of the main causes of defective products. After the operators were trained, the evaluation was carried out again and the quantity of defective products was analyzed within 5 weeks of implementation.

\subsection{Security and Health at Work}

The implementation of this tool was carried out for 4 weeks aiming to guarantee better working conditions. Through the IPER matrix, it was possible to identify the hazards and risks in M1Pr2. Accidents and work incidents and inappropriate use of PPEs were recorded, which resulted in staff absenteeism and economic losses for the company. Once the training was carried out, these causes were analyzed, and the following results were obtained as shown in Table 1.

Table 1. Work permits before and after implementation

\begin{tabular}{l|l|l|l|l}
\hline & Week 1 & Week 2 & Week 3 & Week 4 \\
\hline Permissions (Before) & 3 & 2 & 4 & 4 \\
\hline Permissions (After) & 2 & 1 & 2 & 2 \\
\hline
\end{tabular}




\subsection{Supplier Approval}

This tool was implemented because spare parts and parts used in the machinery had poor quality, last a short time and cause more damage to it. That is why it is validated and results are obtained through a quality questionnaire, taking into account its quality standards. Then, reports is made of each supplier and thus see the most summarized situation.

\subsection{Jidoka}

The implementation of this tool was 5 weeks, which was based on the AMEF to detect the main fault and on which machine it frequents most. Workers were trained to allow them to intervene in some manufacturing process to avoid defective products. The results of the pilot development are shown in Table 2 .

Table 2. Products reprocessed before and after implementation

\begin{tabular}{l|l|l|l|l|l}
\hline & Week 1 & Week 2 & Week 3 & Week 4 & Week 5 \\
\hline \% Before & $9.37 \%$ & $9.05 \%$ & $9.06 \%$ & $8.81 \%$ & $9.31 \%$ \\
\hline \% After & $7.73 \%$ & $7.63 \%$ & $7.75 \%$ & $7.36 \%$ & $7.28 \%$ \\
\hline
\end{tabular}

\subsection{Maintenance Management}

For the implementation of the preventive and autonomous maintenance, the programmed trainings were carried out, obtaining the assistance of $100 \%$ of the operators. To verify that the implementation was favorable for the company under study, the OEE was calculated in each of the machines of the production process. The results of the OEE of the lathe, sanding and riveting machine before and after implementation are exhibited in Tables 3, 4, and 5 .

Table 3. OEE lathe before and after implementation

\begin{tabular}{l|c|c|c|c|c}
\hline & Week 1 & Week 2 & Week 3 & Week 4 & Week 5 \\
\hline OEE Before & $41.46 \%$ & $38.64 \%$ & $46.99 \%$ & $48.14 \%$ & $49.55 \%$ \\
\hline OEE After & $44.73 \%$ & $41.71 \%$ & $50.74 \%$ & $51.90 \%$ & $53.03 \%$ \\
\hline
\end{tabular}

Table 4. OEE sanding before and after implementation

\begin{tabular}{l|c|c|c|c|c}
\hline & Week 1 & Week 2 & Week 3 & Week 4 & Week 5 \\
\hline OEE Before & $40.73 \%$ & $36.01 \%$ & $47.17 \%$ & $47.64 \%$ & $50.97 \%$ \\
\hline OEE After & $41.55 \%$ & $39.59 \%$ & $51.45 \%$ & $52.59 \%$ & $53.93 \%$ \\
\hline
\end{tabular}


Table 5. OEE riveted before and after implementation

\begin{tabular}{l|c|c|c|c|c}
\hline & Week 1 & Week 2 & Week 3 & Week 4 & Week 5 \\
\hline OEE Before & $40.37 \%$ & $37.71 \%$ & $48.15 \%$ & $50.26 \%$ & $50.63 \%$ \\
\hline OEE After & $43.77 \%$ & $40.67 \%$ & $51.08 \%$ & $55.18 \%$ & $55.86 \%$ \\
\hline
\end{tabular}

As you can see, the OEE of the machines has increased. However, this pilot implementation was carried out for only five weeks. Therefore, the OEE is expected to increase the target in the coming weeks.

\subsection{Simulation}

The simulation of the processes of the company M1Pr2 will be executed, with the aim of reducing the process time and defects in each process as shown in Table 6.

Table 6. Improved situation of the company M1Pr2

\begin{tabular}{l|l}
\hline Improvement situation 1 & Improvement situation 2 \\
\hline 220.25 & 214.99 \\
\hline 7.42 & 7.42 \\
\hline 10.36 & 3.25 \\
\hline 0.47 & 2.42 \\
\hline 0.73 & 3.53 \\
\hline 44.87 & 43.85 \\
\hline $53 \%$ & $53 \%$ \\
\hline $54 \%$ & $31 \%$ \\
\hline $15 \%$ & $18 \%$ \\
\hline $34 \%$ & $37 \%$ \\
\hline $49 \%$ & $49 \%$ \\
\hline 8 & 9 \\
\hline 990.93 & $1,025.21$ \\
\hline
\end{tabular}

The time of the products in processes has been reduced from 51.43 to 43.85 pots, which is considerable because they were expected to be reduced with the improvements implemented. Likewise, the time of the tail of the Lathe has been reduced from 22.45 to $7.42 \mathrm{~min}$, which is what was expected since this is also a critical machine for the company. 


\section{Analysis of Results}

The results obtained from the measurement of the indicators before and after the implementation of the improvement tools that were proposed for the problem under study are shown in Table 7.

As can be seen in Fig. 18, for the TPM tool the OEE was used as a measurement indicator where it can be seen that a percentage of $44.3 \%$ on average was obtained before implementation and after the implementation of the improvement reached $48 \%$ on average. Likewise, for the measurement of the pilot implementation of the occupational health and safety tool, the number of absent operators was evaluated before the implementation with a result of 13 absent operators and after the implementation it was reduced to 7 absent operators. Finally, for the Jidoka improvement tool, the percentage of reprocessed products was calculated before implementation obtaining $9.14 \%$ and after implementation, $7.55 \%$ not achieving the target value, but it is no longer a critical value. It should be noted that an improvement was achieved after the implementations, but the optimal value was not achieved because only the implementation of each tool was made between 4 and 5 weeks.

Table 7. Scenario summary

\begin{tabular}{l|l|l|l|l}
\hline Variables & Actual & Pessimist & Normal & Optimist \\
\hline OEE & $44.96 \%$ & $46.67 \%$ & $48.42 \%$ & $55.45 \%$ \\
\hline \% Products with defects & $10.30 \%$ & $9.90 \%$ & $8.38 \%$ & $6.30 \%$ \\
\hline Number of absent operators & 13 & 10 & 7 & 4 \\
\hline Number of parts with defects & $9.14 \%$ & $8.76 \%$ & $7.75 \%$ & $5.20 \%$ \\
\hline
\end{tabular}

\section{Conclusions}

After the analysis, the study showed that the main problem of the company was the low machine availability. Likewise, this paper shows the success on the application of talent management tools, Jidoka, TPM, supplier approval and occupational health and safety, to fight the issue of the production process.

\section{References}

1. Kishimoto, K., Medina, G., Sotelo, F., Raymundo, C.: Application of lean manufacturing techniques to increase on-time deliveries: case study of a metalworking company with a make-to-order environment in Peru (2020). https://doi.org/10.1007/978-3-030-25629-6_148

2. Lavado, K., Ramos, W., Carvallo, E., Raymundo, C., Dominguez, F.: Telecommunications tower kits manufacturing model based on Ikea's approach to minimize the return due to missing parts in a metalworking enterprise kit (2020). https://doi.org/10.1007/978-3-03027928-8_146 
3. Gujar, S., Moroliya, M.R.: Increasing the productivity by using work-study in a manufacturing industry-literature review. Int. J. Mech. Prod. Eng. Res. Dev. (2018). https://doi.org/10. 24247/ijmperdapr201841, https://www.scopus.com

4. Huamán, J., Llontop, J., Raymundo, C., Dominguez, F.: Production management model based on lean manufacturing focused on the human factor to improve productivity of small businesses in the metalworking sector (2020). https://doi.org/10.1007/978-3-030-27928-8_ 128

5. Moscoso, C., Fernandez, A., Viacava, G., Raymundo, C.: Integral model of maintenance management based on TPM and RCM principles to increase machine availability in a manufacturing company (2020). https://doi.org/10.1007/978-3-030-25629-6_137 